\title{
Ortaokul 8. Sınıf Öğrencilerinin Türk Müziği Biçimlerini Tanıma Durumlarının İncelenmesi ${ }^{1}$
}

\author{
DOI: 10.26466/opus.799734
}

\author{
Kubilay Perdakçıŏlu*- Murat Kamil İnanıc1** \\ * Bilim Uzmanı, Erzurum Atatürk Üniversitesi \\ E-Posta: kubisolist@gmail.com \\ ORCID: 0000-0003-1909-3203 \\ ** Dr. Öğr. Üyesi, Erzurum Atatürk Üniversitesi \\ E-Posta: muratkamilinanici@hotmail.com \\ ORCID: $\underline{0000-0002-0908-9668}$
}

\begin{abstract}
Öz
Bu araştırmada, ortaokul 8. sını öğrencilerinin Türk Müziğ̀i biçimlerini tanıma durumlarının ne düzeyde gerçekleştiğinin incelenmesi amaçlanmıştır. Araştırmada, nicel araştırma desenlerinden betimsel tarama modeli kullanılmıştır. Veri toplama aracı olarak araştırmacılar tarafindan hazırlanan "Kişisel Bilgi Formu" ve ortaokul 8. sınf öğrencilerinin Türk müziği biçimlerini tanıma durumların belirlemeye yönelik "Türk Müziği Biçimlerini Tanıma Formu" kullanılmıştır. Hazırlanan "Türk Müziği Biçimlerini Tanıma Formu" nda madde güçlükleri aynı olarak kabul edildiğinden iç tutarlık KR-20 testi ile hesaplanmıştır (alfa katsayısı=.690). Araştırmanın verilerinin analizinde yüzde ve frekans analizi kullanılmıştır. Sosyoekonomik çevreye dair gruplar arası tanıma durumları ise tek yönlü ANOVA ile elde edilmiştir. Araştırmadan elde edilen bulgulara göre öğrencilerin en yüksek oranda tanıdıkları Türk müziği biçimlerinin Horon, Zeybek, Halay ve Bar olduğu belirlenmiştir. Öğrencilerin tanıma formundan aldıklar toplam puanlara göre Türk Müziği Biçimlerini orta düzeyde tanıdıkları, genel puan dağglımının toplam 15 puan üzerinden ortalama 7.15 puan civarında olduğu ve 5 ile 10 puanlar arasında yı̆̆ılldığı sonucuna ulaşılmıştır. Ayrıca öğrencilerin Türk Halk Müziğgi müzik biçimlerini Türk sanat müziği biçimlerine göre daha fazla oranda tanıdıkları belirlenmiştir. Öğrencilerin öğrenim gördükleri okulun bulunduğu sosyoekonomik çevrenin ise bazı Türk müziği biçimlerini tanımada anlamlı farklılık oluşturduğu görülmüştür.
\end{abstract}

Anahtar Kelimeler: ortaokul öğrencileri, Türk müziği biçimleri, müzik eğitimi, müzik öğretim programi, sosyoekonomik çevre

\footnotetext{
${ }^{1}$ Bu araştırma ikinci yazar danışmanlı̆ı̆ında birinci yazar tarafından hazırlanan yüksek lisans tez çalışmasından üretilmiştir.
} 
ISSN:2528-9527

E-ISSN : 2528-9535

YIl Year: 10

Cilt Volume: 17

Sayı Issue: 33

Uluslararası Toplum Araştırmaları Dergisi

International Journal of Society Researches

Ocak January 2021

Makalenin Gelis Tarihi Received Date: 24/09/2020

Makalenin Kabul Tarihi Accepted Date: 29/01/2021

\title{
Examination of The 8th Grade Secondary School Students' Identification of Turkish Music Forms
}

\begin{abstract}
The aim of this study is to analyze 8th grade secondary school students' identification process of Turkish Music forms. In this study, among the quantitative methods, the descriptive scanning model has been used. "Personal Information Form" prepared by the researchers as a data collecting tool and "Identification of Turkish Music Form" have been used to find out the 8th grade secondary school students' identification of Turkish Music. Considering item distinctiveness is at the same level in all questions of the "Students' Identification of Turkish Music Form", internal consistency has been calculated via KR20 test (Alpha value $=.690$ ). Frequencies and percentages have been used for analyzing the data. Identification process within groups that have been divided socioeconomically has been acquired by using oneway ANOVA. According to the findings obtained from the research, students have recognized Horon, Zeybek, Halay and Bar music forms at the highest rate. Students are able to identify Turkish Music Forms at intermediate level according to their total score, general score range has been approximately 7.15 on a 15 point scale and between 5 and 10 points. In addition, the students knew Turkish Folk Music forms more than Turkish art music forms It was observed that the socioeconomic environment in which the school where the students are studying creates a significant difference in recognizing some forms of Turkish music.
\end{abstract}

Keywords: secondary school students, Turkish music forms, music education, music teaching curriculum, socioeconomic environment 


\section{Giriş}

İnsanoğlunun varoluşuyla birlikte ortaya çıkan ve milyonlarca yıldır gelişerek devam eden müzik, bireylerin yaşamının ve gelişiminin doğal bir parçası ve ihtiyacıdır (Dikici Sığırtmaç, 2014; Fox veSchirrmacher, 2014; HKSR, 2003). İlkokul-ortaokul çağ 1 çocuklarının yaşamında da müziğin yeri ve önemi çok büyüktür. Bu dönemlerde çocuklar için müzik, hem kullanışlı bir eğitim aracı, hem etkili bir eğitim yöntemi hem de önemli bir eğitim alanıdır (Uçan, Yıldız ve Bayraktar, 1999). Müziksel işlevler çocuğun hem bireysel yaşamında, hem kendi çevresindeki insanlar ve diğer canlılarla ilişkilerinde ve hem de onlara katkılarında çok etkin ve belirleyici rol oynamaktadır (Uçan, 1999). Bu sebeple müzik eğitimini sadece öğrencilerin boş zamanlarına yönelik ilgi ve eğlence biçimi olarak değerlendirmek doğru değildir. Müzik eğitimi öğrencilerin müfredatlarında merkezi bir yere sahiptir. Çünkü öğrencilerin gelişimleri için vazgeçilmez öğrenme deneyimleri sağlar. Okullar öğrencilere kaliteli müzik eğitimi vermek için müfredatlarını geliştirmelerine önem vermelidir (HKSR, 2003).

Müzikal etkinliklere katılım çocuklarda özgüven, yaratıcılık, eleştirel düşünme, entelektüel ve ahlaki gelişim, estetik duyarlılık, başkalarıyla etkileşime girme, farklı bakış açıları kazanma özdisiplin ve sorumluluk gibi birçok bilişsel, duyuşsal, psikomotor ve sosyal gelişimine katkıda bulunarak bütünsel bir gelişim sağlar (Barış ve Özata, 2009; HKSR, 2003; Uçan, 1996). Ayrıca çocuk müzik eğitimi ile bilgi sahibi olmayı, bilgiyi seçmeyi, eleştiri yapmayı öğrenir, müzik t eğitiminin faydaları yardımıyla kendi hayatına yön verebilir (Türkmen, 2010). Bunun yanı sıra müzik, kültürel belleğin ve toplumsal bilinçaltında yerleşik bulunan kültürel değerlerin taşıyıcısı olarak kültürel kimliğin oluşumunda, korunmasında ve sonraki nesillere aktarılmasında da önemli rol oynar (Helvac1, 2006). Nitekim Konfüçyüs, müziğin toplumdaki ahlaki değerleri geliştirmede ve geleneği korumdaki önemine dikkat çeker (HKSR, 2003). Müzik insanlar için geçmiş ve gelecek arasında bağlantı kuran bir köprü niteliğindedir (Şenocak, 2005). Müzik, içerisinde yaşamakta olduğu kültürel yapının özelliklerini yansıtma işlevini yerine getirirken, içerisinde bulunduğu kültürel yapıyı etkilemekte ve aynı zamanda kendisi de etkilenmektedir (İmik, 2011). Müziksel gelenek, müzik kültürünün bel kemiğidir. Bu durum ülkemiz genel müzik kültüründe çok açık biçimde kendini göste- 
rir. Bu nedenle geleneksel müziklerimiz geçmişten bu yana genel müzik kültürümüzün belkemiği, ana omurgası ve ana ekseni durumunda ve konumundadır (Uçan, 2018). Müziğin toplumsal ve kültürel önemi ile etkileme işlevi ancak okullarda verilen müzik eğitimi yoluyla gerçekleşebilir. Öğrenciye okulda kazandırılan müzikler, müzik anlayışı ve beğenisi, gitgide aileye ve topluma yerleşerek sürdürülebilir hale gelir (Sun, 1969). Kendi kültüründen uzaklaşan bir neslin toplum kültürünü gelecek nesillere aktarması oldukça zordur (İmik, 2012). Çağdaş müzik eğitiminde bireyler ya da öğrenciler genellikle müziksel geleneğin son örüntüleri içinde biçimlenir. Bu sebeple en gelişmiş toplumların genel müzik eğitiminde geleneksel müzikler önemle yer alır (Uçan, 2018). Cesarone (1999) nitelikli bir müzik eğitiminde geleneksel müzik örneklerini kullanarak öğrencilerde geleneksel kültürü anlamlandırma ve kendi kültürlerine karşı saygıyı duymayı geliştirmenin önemine dikkat çekmiştir (akt. Nevruz, 2018).

Her toplumun kendi milli değerleri ve kuralları çerçevesinde oluşan bir müzik sanatı vardır. Türk müziği de kendi örf, adet ve gelenekleri çerçevesinde doğmuş, şekillenmiş ve gelişmiştir böylece Türk kültürünün bir parçası olmuştur (Kardeş, 2013). Türk müziği kendine özgü karakteristik ve yapısal özellikleri içinde barındıran bir müziktir. Makamsal olması bu özelliklerinden biridir (Yahya,Kaçar, 2009). Geleneksel Türk müzikleri “Geleneksel Türk Halk Müziğii" ve "Geleneksel Türk Sanat Müziği"den oluşmaktadır. Geleneksel Türk halk müziği, halkın ortak duygu ve düşüncelerini yansıtan, halk içinde her zaman var olan halk sanatçıları tarafından yakılmış, yaratılmışbestelenmiş, değişimler ve yoğrulmalarla dilden dile, telden tele, kulaktan kulağa yayılarak geçmişten günümüze ulaşmış geleneksel müziktir (Büyükyıldız, 2009). Geleneksel Türk sanat müziği ise tarihi süreç içerisinde tek sesli olarak gelişen, yenilenen; kendine öz makam, usul ve tekniğe sahip, sözsüz ve sözlü Türk sanat türüdür (Şanll, 2007). İlgili alan yazın incelendiğinde müzikal biçimlerin çeşitli başlıklar altında sınıflandırıldıkları görülmektedir. Bu sınıflandırmalar, müzikal biçimlerin ortaya çıkış koşulları (kent ya da kırsal müzik), kullanıldıkları alanlar (dini ya da din dışı müzik) ve seslendirilme biçimlerine (sözlü ya da sözsüz müzik) göre yapılmaktadır (Emnalar, 1998; Yahya, Kaçar, 2009). Türk sanat müziğinde bulunan müzik biçimlerine örnek olarak Mevlevi ayini, peşrev, şarkı, saz semaisi, longa; Türk halk müziğinde 
bulunan müzik biçimlerine ise kırık hava, uzun hava, deyiş, ilahi, nefes, zeybek, bar, horon, hora, halay örnek olarak gösterilebilir (Demirsipahi, 1975; Dursun, 2017; Yahya, Kaçar, 2009; Özbek, 2014; Özkan, 2014).

Ülkemizde 8. sınıflar için hazırlanan MEB (2018) Müzik Öğretim Programı "dinleme-söyleme", "müziksel alg1 ve bilgilenme", "müziksel yaratıc1lık" ve "müzik kültürü" öğrenme alanlarından oluşturulmuştur. Özellikle "müzik kültürü" öğrenme alanında "Türk müziği biçimlerini tanır" kazanımına yer verilmiş ve öğrencilerden "mevlevî ayini, peşrev, saz semaisi, longa, kırık hava, uzun hava, şarkı, ilahi, nefes, deyiş vb. müzik biçimlerini tanıması beklenmektedir. Bu sebeple öğrencilerin bu kazanıma ulaşıp ulaşmadıklarını belirlemek önemli olarak görülmektedir.

Bu araştırmada, ortaokul 8. sınıf öğrencilerinin Türk müziği biçimlerini tanıma durumlarının incelenmesi amaçlanmıştır. "Öğrencilerin, ortaokul 8. sınıf müzik dersi programında yer alan Türk müziği biçimlerini tanıma durumlarının düzeyi nedir?" sorusu araştırmanın problem cümlesini oluşturmaktadır. Problem cümlesine dayalı olarak oluşturularak yanıtı aranan alt problemler ise şu şekildedir:

- Öğrencilerin "Mevlevi ayini" biçimini tanıma durumları ne düzeydedir?

- Öğrencilerin "Peşrev" biçimini tanıma durumları ne düzeydedir?

- Öğrencilerin "Saz semaisi" biçimini tanıma durumları ne düzeydedir?

- Öğrencilerin "Longa” biçimini tanıma durumları ne düzeydedir?

- Öğrencilerin "Kırık hava" biçimini tanıma durumları ne düzeydedir?

- Öğrencilerin "Uzun hava" biçimini tanıma durumları ne düzeydedir?

- Öğrencilerin "Şarkı" biçimini tanıma durumları ne düzeydedir?

- Öğrencilerin "İlahi" biçimini tanıma durumları ne düzeydedir?

- Öğrencilerin "Nefes" biçimini tanıma durumları ne düzeydedir?

- Öğrencilerin "Deyiş̧" biçimini tanıma durumları ne düzeydedir?

- Öğrencilerin "Zeybek" biçimini tanıma durumları ne düzeydedir?

- Öğrencilerin "Bar" biçimini tanıma durumları ne düzeydedir?

- Öğrencilerin "Horon" biçimini tanıma durumları ne düzeydedir?

- Öğrencilerin "Hora" biçimini tanıma durumları ne düzeydedir?

- Öğrencilerin "Halay" biçimini tanıma durumları ne düzeydedir?

- Öğrencilerin Türk müziği biçimlerini tanıma durumları ne düzeydedir?

- Öğrencilerin tanıyamadıkları Türk müziği biçimlerine verdikleri cevaplar nelerdir? 
- Öğrencilerin ortaokul 8. sınıf müzik dersi programında yer alan Türk müziği biçimlerini tanıma durumları öğrencilerin bulundukları sosyoekonomik çevreye bağlı olarak farklılık göstermekte midir?

\section{Yöntem}

Bu bölümde araştırmanın modeli, evreni ve örneklemi, veri toplama araçları, verilerin toplanması ve verilerin analizi başlıklarına yer verilmiştir.

\section{Araştırmanın Modeli/ Deseni}

Bu araştırmada, ortaokul 8. sınıf öğrencilerinin Türk Müziği biçimlerini tanıma durumlarının ne düzeyde gerçekleştiğinin incelenmesi amaçlandığından nicel araştırma desenlerinden betimsel tarama modeli kullanılmıştır. "Betimsel tarama modeli geçmişte ya da halen var olan bir durumu, var olduğu şekliyle betimlemeyi amaçlayan araştırma yaklaşımıdır" (Karasar, 2007, s.77).

\section{Evren-Örneklem}

Araştırma 2018-2019 eğitim-öğretim yılı Erzurum il merkezinde Milli Eğitim Müdürlüğü'ne bağlı ortaokullarda öğrenim gören 2848 . sınıf öğrencisi ile yapılmıştır. Katılımcıların belirlenmesinde küme örnekleme yöntemi kullanılmıştır. Kümelere göre örnekleme yönteminde evren küme adı verilen gruplara ayrılır, her küme bir örnekleme birimi olarak tanımlanır. Tesadüfi olarak seçilen kümeler bir araya getirilerek örneklem oluşturulur (Çömlekçi, 2001, s.90). Bu araştırmada da, okulların bulunduğu sosyoekonomik çevre dikkate alınmış ve alt, orta, üst gelirli olarak kümelenmiştir. Kümeler içerisinden rastgele seçilen 5 okulda bulunan 284 öğrenci ile çalışma yapılmıştır. Çalışma grubunun özelliklerine ilişkin bilgiler Tablo 1. 'de verilmiştir. 
Tablo 1. Çalışma Grubunun Demografik Özellikleri

\begin{tabular}{|c|c|c|c|}
\hline Özellikler & & $\mathrm{n}$ & $\%$ \\
\hline \multirow{2}{*}{ Cinsiyet } & $\mathrm{K} ı \mathrm{z}$ & 144 & 50.7 \\
\hline & Erkek & 140 & 49.3 \\
\hline \multirow{5}{*}{ Anne Eğitim Durumu } & Okur-Yazar & 25 & 8.8 \\
\hline & İlkokul & 118 & 41.5 \\
\hline & Ortaokul & 100 & 35.2 \\
\hline & Lise & 30 & 10.6 \\
\hline & Lisans & 11 & 3.9 \\
\hline \multirow{6}{*}{ Baba Eğitim Durumu } & Okur-Yazar & 11 & 3.9 \\
\hline & İlkokul & 54 & 19.0 \\
\hline & Ortaokul & 89 & 31.3 \\
\hline & Lise & 89 & 31.3 \\
\hline & Lisans & 35 & 12.3 \\
\hline & Lisansüstü & 6 & 2.1 \\
\hline \multirow{2}{*}{ Annenin Çalışma Durumu } & Çalışıyor & 25 & 8.8 \\
\hline & Çalışmiyor & 259 & 91.2 \\
\hline \multirow{2}{*}{ Babanın Çalışma Durumu } & Çalışıyor & 250 & 88.0 \\
\hline & Çalışmiyor & 34 & 12 \\
\hline \multirow[t]{4}{*}{ Annenin Mesleği } & Ev hanımı & 261 & 91.9 \\
\hline & Serbest Meslek & 13 & 4.6 \\
\hline & Memur & 9 & 3.2 \\
\hline & İşçi & 1 & 0.4 \\
\hline \multirow{6}{*}{ Babanın Mesleği } & Serbest Meslek & 166 & 58.5. \\
\hline & Memur & 53 & 18.7 \\
\hline & İşsiz & 29 & 10.2 \\
\hline & 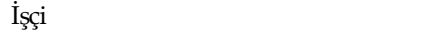 & 27 & 9.5 \\
\hline & $\begin{array}{l}\text { Profesyonel Meslek (Akademisyen, } \\
\text { Mühendis, Doktor } \mathrm{Vb} \text {.) }\end{array}$ & 6 & 2.1 \\
\hline & Emekli & 3 & 1.1 \\
\hline
\end{tabular}

\section{Veri Toplama Araçlarn}

Araştırmada veri toplama aracı olarak araştırmacılar tarafından hazırlanan "Kişisel Bilgi Formu" ve ortaokul 8. sınıf öğrencilerinin Türk müziği biçimlerini tanıma durumlarını belirlemeye yönelik "Türk Müziği Biçimlerini Tanıma Formu" kullanılmıştır. Araştırmada kullanılan "Kişisel Bilgi Formu" öğrencilerin demografik özellikleriyle ilgili bilgileri elde etmek amacıyla araştırmacılar tarafından geliştirilmiş ve çalışmaya katılan öğrencilerin yaşı, cinsiyeti, anne-baba öğrenim durumu, çalışma durumu, mesleği hakkında bilgi edinebilmek için sorular yer almıştır. Araştırmada, öğrencilerin Türk Müziği türlerini tanıma durumlarını ortaya koymak amacıyla araştırmacılar tarafından "Türk Müziği Biçimlerini Tanıma Formu" geliştirilmiştir. Tanıma formunun geliştirilmesi aşamasında, Milli Eğitim Bakanlığı Müzik Dersi müfredatı 
içerisinde yer alan kazanımlar incelenerek Türk Müziğine ait türler derlenip ele alınmıştır. Araştırmada kullanılan "Türk Müziği Biçimlerini Tanıma Formunun" hazırlanma sürecinde alan yazın taranarak Türk müziğinin temel unsurları olan Türk halk müziği ve Türk sanat müziği içerisinde yer alan "Mevlevi ayini, peşrev, saz semaisi, longa, kırık hava, uzun hava, şarkı, ilahi, nefes, deyiş vb." (MEB, 2018, s.34) müzik biçimlerinden eser listesi hazırlanmıştır. Dinletilecek olan eserlerin seçiminde 3 Türk müziği uzmanından görüşler alınmıştır. Uzmanlardan dinletilecek eserlerin "öğrencilerin düzeyine uygunluğu", "Türk müziği biçimlerini yansıtması açısından uygunluğu”, "8. sınıf kazanımlarını kapsaması açısından uygunluğu", "8. sınıf öğrencileri tarafından anlaşılabilir olması açısından uygunluğu, "eser sıralaması, öğrencilerin değerlendirme yapmaları açısından uygunluğu", "dinletilecek eserler için belirlenen süre, öğrencilerin değerlendirme ve puanlama yapmaları açısından uygunluğu" açısından değerlendirmeleri sağlanmış ve gerekli düzeltmeler yapılmıştır. Veri toplama aracında verilmesi beklenen cevaplar (1) bir, verilmesi istenmeyen cevaplar (0) sıfır olarak kodlanmıştır. Uygulama sonrası elde edilen veriler ile Kuder-Richardson testi yapılmış ve Alpha değeri $=.690$ bulunmuştur.

\section{Verilerin Toplanmast}

Araştırmada gerekli izinlerin alınma sürecinin tamamlanmasından sonra belirlenen okullardan gönüllülük esasına dayalı olarak seçilen öğrencilerle kendi sınıflarında toplu olarak çalışılmıştır. Öncelikle uzman görüşleri doğrultusunda belirlenen eser örneklerinin "MP3" formatları araştırmacılar tarafından bilgisayar ortamına kaydedilmiştir. Kaydedilen eserler araştırmacılar tarafından sınıf ortamında öğrencilere dinletilerek öğrencilerin her bir eserin biçimini bireysel olarak dağıtılan "Türk Müziği Biçimlerini Tanıma Formu" ndan seçerek işaretlemeleri sağlanmıştır. Bu işlem yaklaşık olarak 30 dakika sürmüştür.

\section{Verilerin Analizi}

Verilerin analizi aşamasında anketin iç tutarlığı Kuder-Richardson testi ile hesaplanmıştır. Bu tür testlerde maddeler iki durumlu seçeneklerden (Örneğin, doğru-yanlış, evet-hayır... gibi) testin güvenirliği KR-20 veya KR-21 for- 
mülleri ile hesaplanır (Alpar, 2001). Hazırlanan “Türk Müziği Biçimlerini Tanıma Formunda" madde güçlükleri aynı olarak kabul edildiğinden iç tutarlık KR-20 testi ile hesaplanmıştır (Alpha değeri =.690).

Alt problemlere ait verilerin analizinde yüzde ve frekans analizi yapılmış, sosyoekonomik çevreye dair gruplar arası tanıma durumları ise tek yönlü ANOVA testi ile elde edilmiştir.

\section{Bulgular}

Tablo 2. Öğrencilerin Müzik Biçimini Tanıma Durumuna İlişkin Tablo

\begin{tabular}{lllll}
\hline Müzik Biçimleri & Tanıma Durumu & $\mathbf{f}$ & $\mathbf{\%}$ \\
\hline \multirow{2}{*}{ Peşrev } & Tanıma & 170 & 59.9 \\
\cline { 2 - 4 } & Tanmama & 114 & 40.1 \\
\hline \multirow{2}{*}{ Saz Semaisi } & Tanıma & 52 & 18.3 \\
\cline { 2 - 4 } & Tanmama & 232 & 81.7 \\
\hline \multirow{2}{*}{ Longa } & Tanıma & 35 & 12.3 \\
\cline { 2 - 4 } & Tanmama & 249 & 87.7 \\
\hline \multirow{2}{*}{ Kırkk Hava } & Tanıma & 125 & 44.0 \\
\cline { 2 - 4 } & Tanmama & Tanıma & 159 & 56.0 \\
\hline \multirow{2}{*}{ Uzun Hava } & Tanmama & 168 & 59.1 \\
\hline \multirow{2}{*}{ Şark1 } & Tanıma & 116 & 40.9 \\
\cline { 2 - 4 } & Tanmama & 195 & 68.7 \\
\hline \multirow{2}{*}{ Ilahi } & Tanıma & 89 & 31.3 \\
\cline { 2 - 4 } & Tanmama & 183 & 64.4 \\
\hline \multirow{2}{*}{ Nefes } & Tanıma & 101 & 35.6 \\
\cline { 2 - 4 } & Tanmama & 176 & 62.0 \\
\hline \multirow{2}{*}{ Deyiş } & Tanıma & 108 & 38.0 \\
\cline { 2 - 4 } & Tanmama & 68 & 24.0 \\
\hline Zeybek & Tanıma & 216 & 76.0 \\
\cline { 2 - 4 } & Tanmama & 53 & 18.7 \\
\hline Bar & Tanıma & 231 & 81.3 \\
\cline { 2 - 4 } & Tanmama & 244 & 86.0 \\
\hline \multirow{2}{*}{ Horon } & Tanıma & 40 & 14.0 \\
\cline { 2 - 4 } & Tanmama & 218 & 76.8 \\
\hline \multirow{2}{*}{ Hora } & Tanıma & 66 & 23.2 \\
\hline \multirow{2}{*}{ Halay } & Tanmama & 270 & 95.0 \\
\hline & Tanıma & 14 & 5.0 \\
\cline { 2 - 4 } & Tanmama & 104 & 36.7 \\
\cline { 2 - 4 } & Tanma & 180 & 63.3 \\
\hline
\end{tabular}


Tablo 2. incelendiğinde öğrencilerin \%59.9'unun Mevlevi ayini müzik biçimini tanıdığı, \%40.1'inin tanımadığı; \%18.3'ünün peşrev müzik biçimini tanıdığı, \%81.7'sının tanımadığı; \%12.3' ünün saz semaisi müzik biçimini tanıdığı, \%87.7'sinin tanımadığı; \%44'ünün longa müzik biçimini tanıdığı, \%56'sının tanımadığı; \%59.1'inin kırık hava müzik biçimini tanıdığı, \%40.9'unun tanımadığı; \%68.7'sinin uzun hava müzik biçimini tanıdığı, \%31.3'ünün tanımadığı; \%64.4'ünün şarkı müzik biçimini tanıdığı, \%35.6'sının tanımadığı; \%62'sinin ilahi müzik biçimini tanıdığı, \%tanımadığı; \%24'ünün nefes müzik biçimini tanıdığı, \%76'sının tanımadığı; \%18.7'sinin deyiş müzik biçimini tanıdığı, \%81.3' ünün tanımadığı; \%86'sının zeybek müzik biçimini tanıdığı, \%14'ünün tanımadığı; \%76.8' inin bar müzik biçimini tanıdığı, \%23.2'sinin tanımadığı; \%95'inin horon müzik biçimini tanıdı̆̆ı, \%5'inin tanımadığı; \%36.7'sinin hora müzik biçimini tanıdığı, \%63.3'ünün tanımadığı; \%84.9'unun halay müzik biçimini tanıdığı, \%15.1'inin halay müzik biçimini tanımadığı bulgusuna ulaşılmıştır.

Tablo 3. Öğrencilerin Türk Müziği Biçimlerini Tanıma Durumların Betimleyici Tablo

\begin{tabular}{llllllllll}
\hline & N & $\begin{array}{l}\text { Orta- } \\
\text { lama }\end{array}$ & $\begin{array}{l}\text { Or- } \\
\text { tanca }\end{array}$ & Mod & $\begin{array}{l}\text { Min. } \\
\text { Puan }\end{array}$ & $\begin{array}{l}\text { Max. } \\
\text { Puan }\end{array}$ & Toplam & $\begin{array}{l}\text { Standart } \\
\text { Sapma }\end{array}$ & $\begin{array}{l}\text { Standart } \\
\text { Hata }\end{array}$ \\
\hline $\begin{array}{l}\text { Türk Müziği } \\
\begin{array}{l}\text { Biçimlerini } \\
\text { Tanıma } \\
\text { Formu }\end{array}\end{array}$ & 284 & 7.15 & 7 & 7 & 0 & 13 & 2032 & 2.716 & .161 \\
\hline
\end{tabular}

Tablo 3.'e göre araştırmaya katılan öğrencilerin Türk Müziği Biçimlerini Tanıma Formuna verdikleri cevaplar değerlendirildiğinde, en düşük 0 en yüksek 15 olması gereken form sonucuna göre en düşük 0 en yüksek 13 puan aldıklanı, aritmetik ortalamanın 7.15 ve ortanca değerin 7 olduğu görülmüştür. 
Ortaokul 8. Sınıf Öğrencilerinin Türk Müziği Biçimlerini Tanıma Durumlarının İncelenmesi

Tablo 4. Öğrencilerin Türk Müziği Biçimini Tanıma Durumlan İle Öğrenim Gördükleri Okulun Bulunduğu Çevrenin Sosyoekonomik Durumu Arasındaki İlişkiyi Gösterir KiKare Tablosu

\begin{tabular}{|c|c|c|c|c|c|c|c|}
\hline & Gruplar & Tanıma & Tanimama & Toplam & $\chi^{2}$ & sd & $p$ \\
\hline \multirow{3}{*}{$\begin{array}{l}\text { Mevlevi } \\
\text { Ayini }\end{array}$} & Alt sosyoekonomik çevre & 44 & 34 & 78 & \multirow{3}{*}{11.852} & \multirow{3}{*}{2} & \multirow{3}{*}{.003} \\
\hline & Orta sosyoekonomik çevre & 38 & 73 & 111 & & & \\
\hline & Üst sosyoekonomik çevre & 32 & 63 & 95 & & & \\
\hline \multirow{3}{*}{ Peşrev } & Alt sosyoekonomik çevre & 67 & 11 & 78 & \multirow{3}{*}{1.844} & \multirow{3}{*}{2} & \multirow{3}{*}{.398} \\
\hline & Orta sosyoekonomik çevre & 91 & 20 & 111 & & & \\
\hline & Üst sosyoekonomik çevre & 74 & 21 & 95 & & & \\
\hline \multirow{3}{*}{$\begin{array}{l}\text { Saz } \\
\text { Semaisi }\end{array}$} & Alt sosyoekonomik çevre & 63 & 15 & 78 & \multirow{3}{*}{13.050} & \multirow{3}{*}{2} & \multirow{3}{*}{.001} \\
\hline & Orta sosyoekonomik çevre & 107 & 4 & 111 & & & \\
\hline & Üst sosyoekonomik çevre & 79 & 16 & 95 & & & \\
\hline \multirow{3}{*}{ Longa } & Alt sosyoekonomik çevre & 39 & 39 & 78 & \multirow{3}{*}{2.448} & \multirow{3}{*}{2} & \multirow{3}{*}{.294} \\
\hline & Orta sosyoekonomik çevre & 68 & 43 & 111 & & & \\
\hline & Üst sosyoekonomik çevre & 52 & 43 & 95 & & & \\
\hline \multirow{3}{*}{$\begin{array}{l}\text { Kırık } \\
\text { Hava }\end{array}$} & Alt sosyoekonomik çevre & 28 & 50 & 78 & \multirow{3}{*}{28.515} & \multirow{3}{*}{2} & \multirow{3}{*}{.000} \\
\hline & Orta sosyoekonomik çevre & 29 & 82 & 111 & & & \\
\hline & Üst sosyoekonomik çevre & 59 & 36 & 95 & & & \\
\hline \multirow{3}{*}{$\begin{array}{l}\text { Uzun } \\
\text { Hava }\end{array}$} & Alt sosyoekonomik çevre & 29 & 49 & 78 & \multirow{3}{*}{14.070} & & \\
\hline & Orta sosyoekonomik çevre & 44 & 67 & 111 & & 2 & .001 \\
\hline & Üst sosyoekonomik çevre & 16 & 79 & 95 & & & \\
\hline & Alt sosyoekonomik çevre & 34 & 44 & 78 & & & \\
\hline Şarkı & Orta sosyoekonomik çevre & 50 & 61 & 111 & 19.489 & 2 & .000 \\
\hline & Üst sosyoekonomik çevre & 17 & 78 & 95 & & & \\
\hline & Alt sosyoekonomik çevre & 33 & 45 & 78 & & & \\
\hline İlahi & Orta sosyoekonomik çevre & 36 & 75 & 111 & 2.450 & 2 & .294 \\
\hline & Üst sosyoekonomik çevre & 39 & 56 & 95 & & & \\
\hline & Alt sosyoekonomik çevre & 70 & 8 & 78 & & & \\
\hline Nefes & Orta sosyoekonomik çevre & 90 & 21 & 111 & 24.833 & 2 & .000 \\
\hline & Üst sosyoekonomik çevre & 56 & 39 & 95 & & & \\
\hline & Alt sosyoekonomik çevre & 70 & 8 & 78 & & & \\
\hline Deyiş & Orta sosyoekonomik çevre & 88 & 23 & 111 & 5.206 & 2 & .074 \\
\hline & Üst sosyoekonomik çevre & 73 & 22 & 95 & & & \\
\hline & Alt sosyoekonomik çevre & 12 & 66 & 78 & & & \\
\hline Zeybek & Orta sosyoekonomik çevre & 17 & 94 & 111 & .741 & 2 & .690 \\
\hline & Üst sosyoekonomik çevre & 11 & 84 & 95 & & & \\
\hline & Alt sosyoekonomik çevre & 29 & 49 & 78 & & & \\
\hline Bar & Orta sosyoekonomik çevre & 17 & 94 & 111 & 12.659 & 2 & .002 \\
\hline & Üst sosyoekonomik çevre & 20 & 75 & 95 & & & \\
\hline & Alt sosyoekonomik çevre & 8 & 70 & 78 & & & \\
\hline Horon & Orta sosyoekonomik çevre & 5 & 106 & 111 & 7.812 & 2 & .020 \\
\hline & Üst sosyoekonomik çevre & 1 & 94 & 95 & & & \\
\hline & Alt sosyoekonomik çevre & 52 & 26 & 78 & & & \\
\hline Hora & Orta sosyoekonomik çevre & 52 & 59 & 111 & 24.742 & 2 & .000 \\
\hline & Üst sosyoekonomik çevre & 76 & 19 & 95 & & & \\
\hline & Alt sosyoekonomik çevre & 9 & 69 & 78 & & & \\
\hline Halay & Orta sosyoekonomik çevre & 24 & 87 & 111 & 5.991 & 2 & .050 \\
\hline & Üst sosyoekonomik çevre & 10 & 85 & 95 & & & \\
\hline
\end{tabular}


Tablo 4'e göre öğrencilerin müzik biçimi tanıma durumları okulların bulundukları sosyoekonomik çevreye göre farklılaşıp farklılaşmadığı incelenmiştir. Buna göre öğrencilerin Mevlevi $\left(\chi^{2}=11,852\right.$. $\left.\mathrm{p}=.003\right)$; Saz Semaisi $\left(\chi^{2}=13.050, \mathrm{p}=.001\right)$; Kırık Hava $\left(\chi^{2}=28.515 ; \mathrm{p}=.000\right)$; Uzun Hava $\left(\chi^{2}=14.070\right.$; $\mathrm{p}=.001)$; Şark1 $\left(\chi^{2}=19.489 ; \mathrm{p}=.000\right) ;$ Nefes (๑2=24.833; $\left.\mathrm{p}=.000\right)$; $\operatorname{Bar}\left(\chi^{2}=12.659\right.$; $\mathrm{p}=.002)$; Horon $\left(\chi^{2}=7.812 ; \mathrm{p}=.020\right)$; Hora $\left(\chi^{2}=24.742 ; \mathrm{p}=.000\right)$; Halay $\left(\chi^{2}=5.991\right.$; $\mathrm{p}=.050)$ müzik biçimlerini tanıma durumlarının öğrenim gördükleri okulun sosyoekonomik çevresine anlamlı olarak farklılaştığı belirlenmiştir. Buna karşın öğrencilerin Peşrev ( $\chi^{2}=1.844$. $\left.\mathrm{p}=.398\right)$; Longa $\left(\chi^{2}=2.448 ; \mathrm{p}=.294\right) ;$ İlahi (๑2=2.450; $\mathrm{p}=.294)$; Deyiş $\left(\chi^{2}=5.206 ; \mathrm{p}=.074\right)$; Zeybek $\left(\chi^{2}=.741 ; \mathrm{p}=.690\right)$ müzik biçimlerini tanıma durumlarının öğrenim gördükleri okulun sosyoekonomik çevresine anlamlı olarak farklılaşmadığı tespit edilmiştir.

Tablo 5. Öğrencilerin Tanıyamadıkları Türk Müziği Biçimlerine Verdikleri Cevaplara İlişkin Bulgular

\begin{tabular}{|c|c|c|c|c|c|c|c|c|c|c|c|c|c|c|c|c|}
\hline & \multicolumn{2}{|c|}{$\begin{array}{l}\text { Mevlevi } \\
\text { Ayini }\end{array}$} & \multicolumn{2}{|c|}{ Peşrev } & \multicolumn{2}{|c|}{$\begin{array}{l}\text { Saz } \\
\text { Semaisi }\end{array}$} & \multicolumn{2}{|c|}{ Longa } & \multicolumn{2}{|c|}{$\begin{array}{l}\text { Kurık } \\
\text { Hava }\end{array}$} & \multicolumn{2}{|c|}{$\begin{array}{l}\text { Uzun } \\
\text { Hava }\end{array}$} & \multicolumn{2}{|c|}{ Şarkı } & \multicolumn{2}{|c|}{ İlahi } \\
\hline & $\mathrm{f}$ & $\%$ & $\mathrm{f}$ & $\%$ & $\mathrm{f}$ & $\%$ & $\mathrm{f}$ & $\%$ & $\mathrm{f}$ & $\%$ & $\mathrm{f}$ & $\%$ & $\mathrm{f}$ & $\%$ & $\mathrm{f}$ & $\%$ \\
\hline 离 & 170 & 59.9 & 9 & 3.1 & 5 & 1.8 & 4 & 1.4 & 0 & 0 & 0 & 0 & 7 & 2.4 & 40 & 14 \\
\hline 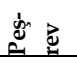 & 27 & 9.5 & 52 & 18.3 & 68 & 24 & 29 & 10.2 & 5 & 1.8 & 7 & 2.4 & 4 & 1.4 & 9 & 3.1 \\
\hline సૈ : & 13 & 4.6 & 98 & 34.6 & 35 & 12.3 & 32 & 11.2 & 39 & 13.8 & 12 & 4.2 & 6 & 2.1 & 5 & 1.8 \\
\hline ฮี ఝ & 11 & 3.9 & 13 & 4.6 & 15 & 5.2 & 125 & 44 & 9 & 3.1 & 9 & 3.1 & 18 & 6.3 & 7 & 2.4 \\
\hline 步 & 7 & 2.4 & 17 & 6 & 16 & 5.6 & 18 & 6.3 & 168 & 59.1 & 7 & 2.4 & 9 & 3.1 & 5 & 1.8 \\
\hline 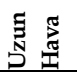 & 4 & 1.4 & 1 & 0.3 & 56 & 19.7 & 0 & 0 & 2 & 0.7 & 195 & 68.7 & 0 & 0 & 1 & 0.3 \\
\hline $\begin{array}{l}\overrightarrow{7} \\
\text { 心̆ } \\
\text { 心 }\end{array}$ & 14 & 5 & 17 & 6 & 10 & 3.6 & 15 & 5.2 & 19 & 6.7 & 1 & 0.3 & 183 & 64.4 & 2 & 0.7 \\
\hline .ี & 19 & 6.7 & 3 & 1 & 3 & 1 & 17 & 6 & 3 & 1 & 3 & 1 & 4 & 1.4 & 176 & 62 \\
\hline $\begin{array}{l}\stackrel{0}{0} \\
\tilde{z}\end{array}$ & 22 & 7.8 & 19 & 6.7 & 5 & 1.8 & 4 & 1.4 & 11 & 3.9 & 7 & 2.4 & 5 & 1.8 & 20 & 7 \\
\hline . & 9 & 3.1 & 24 & 8.4 & 36 & 12.7 & 17 & 6 & 9 & 3.1 & 14 & 5 & 19 & 6.7 & 3 & 1 \\
\hline స्ञ & 0 & 0 & 4 & 1.4 & 1 & 0.3 & 1 & 0.3 & 3 & 1 & 3 & 1 & 2 & 0.7 & 4 & 1.4 \\
\hline ڤี & 2 & 0.7 & 4 & 1.4 & 6 & 2.1 & 10 & 3.6 & 2 & 0.7 & 0 & 0 & 4 & 1.4 & 3 & 1 \\
\hline
\end{tabular}




\begin{tabular}{|c|c|c|c|c|c|c|c|c|c|c|c|c|c|c|c|c|}
\hline 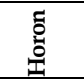 & 0 & 0 & 3 & 1 & 5 & 1.8 & 0 & 0 & 1 & 0.3 & 0 & 0 & 0 & 0 & 1 & 0.3 \\
\hline 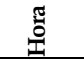 & 4 & 1.4 & 14 & 5 & 45 & 15.9 & 13 & 4.6 & 28 & 9.9 & 14 & 5 & 2 & 0.7 & 8 & 2.8 \\
\hline \multirow[t]{3}{*}{ 离 } & 5 & 1.8 & 4 & 1.4 & 2 & 0.7 & 1 & 0.3 & 0 & 0 & 1 & 0.3 & 3 & 1 & 0 & 0 \\
\hline & \multicolumn{2}{|c|}{ Nefes } & \multicolumn{2}{|c|}{ Deyiş } & \multicolumn{2}{|c|}{ Zeybek } & \multicolumn{2}{|l|}{ Bar } & \multicolumn{2}{|c|}{ Horon } & \multicolumn{2}{|c|}{ Hora } & \multicolumn{2}{|c|}{ Halay } & & \\
\hline & $\mathrm{f}$ & $\%$ & $\mathrm{f}$ & $\%$ & $\mathrm{f}$ & $\%$ & $\mathrm{f}$ & $\%$ & $\mathrm{f}$ & $\%$ & $\mathrm{f}$ & $\%$ & $\mathrm{f}$ & $\%$ & & \\
\hline 离 & 35 & 12.3 & 5 & 1.8 & 0 & 0 & 0 & 0 & 2 & 0.8 & 3 & 1 & 4 & 1.4 & & \\
\hline 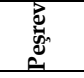 & 32 & 11.2 & 27 & 9.5 & 5 & 1.8 & 6 & 2.1 & 0 & 0 & 7 & 2.4 & 6 & 2.1 & & \\
\hline ஸू & 8 & 2.8 & 8 & 2.8 & 6 & 2.1 & 7 & 2.4 & 4 & 1.4 & 11 & 3.9 & 0 & 0 & & \\
\hline $\begin{array}{l}\text { ⿷匚 } \\
\text { ప్ర }\end{array}$ & 13 & 4.6 & 22 & 7.8 & 3 & 1 & 16 & 5.7 & 3 & 1 & 17 & 6 & 3 & 1 & & \\
\hline 曾疍 & 5 & 1.8 & 9 & 3.1 & 12 & 4.2 & 6 & 2.1 & 0 & 0 & 5 & 1.8 & 0 & 0 & & \\
\hline 志 & 9 & 3.1 & 9 & 3.1 & 0 & 0 & 0 & 0 & 3 & 1 & 4 & 1.4 & 0 & 0 & & \\
\hline 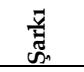 & 8 & 2.9 & 4 & 1.4 & 4 & 1.4 & 4 & 1.4 & 0 & 0 & 3 & 1 & 0 & 0 & & \\
\hline 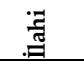 & 22 & 7.8 & 17 & 6 & 4 & 1.4 & 3 & 1 & 0 & 0 & 9 & 3.1 & 1 & 0.3 & & \\
\hline 怤 & 68 & 24 & 83 & 29.2 & 22 & 7.8 & 9 & 3.1 & 1 & 0.3 & 7 & 2.4 & 1 & 0.3 & & \\
\hline 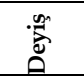 & 29 & 10.2 & 53 & 18.7 & 16 & 5.7 & 1 & 0.3 & 4 & 1.4 & 46 & 16.1 & 4 & 1.4 & & \\
\hline 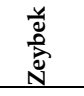 & 2 & 0.7 & 9 & 3.1 & 244 & 86 & 3 & 1 & 1 & 0.3 & 5 & 1.8 & 2 & 0.7 & & \\
\hline ڤี & 7 & 2.4 & 7 & 2.4 & 6 & 2.1 & 218 & 76.8 & 3 & 1 & 7 & 2.4 & 6 & 2.1 & & \\
\hline : & 0 & 0 & 0 & 0 & 0 & 0 & 0 & 0 & 270 & 95 & 3 & 1 & 1 & 0.3 & & \\
\hline 荧 & 16 & 5.7 & 15 & 5.2 & 5 & 1.8 & 9 & 3.1 & 6 & 2.1 & 104 & 36.7 & 1 & 0.3 & & \\
\hline$\frac{\vec{\pi}}{\pi}$ & 5 & 1.8 & 3 & 1 & 2 & 0.7 & 11 & 3.9 & 0 & 0 & 6 & 2.1 & 241 & 84.9 & & \\
\hline
\end{tabular}

Tablo 5'e göre Mevlevi ayini müzik biçimini tanıyamayan öğrenciler bu müzik biçimine \%14 oranında ilahi, \%12.3 oranında nefes; Peşrev müzik biçimini tanıyamayan öğrenciler bu müzik biçimine \%24 oranında saz semaisi, \%11.2 oranında nefes; Saz semaisi müzik biçimini tanıyamayan öğrenciler bu 
müzik biçimine \%34.6 oranında peşrev, \%13.8 oranında kırık hava; Longa müzik biçimini tanıyamayan öğrenciler bu müzik biçimine , $\% 7.8$ oranında deyiş; \%6.3 oranında şarkı; Kırık hava müzik biçimini tanıyamayan öğrenciler bu müzik biçimine \%6.3 oranında longa, \%6 oranında peşrev; Uzun hava müzik biçimini tanıyamayan öğrenciler bu müzik biçimine $\% 19.7$ oranında saz semaisi, \%3.1 oranında nefes, \%3.1 oranında deyiş; Şarkı müzik biçimini tanıyamayan öğrenciler bu müzik biçimine $\% 6.7$ oranında kırık hava, $\% 6$ oranında peşrev; İlahi müzik biçimini tanıyamayan öğrenciler bu müzik biçimine \%7.8 oranında nefes, \%6.7 oranında Mevlevi ayini,; Nefes müzik biçimini tanıyamayan öğrenciler bu müzik biçimine \%7.8 oranında Mevlevi ayini, \%7.8 oranında zeybek; Deyiş müzik biçimini tanıyamayan öğrenciler bu müzik biçimine \%16.1 oranında hora, \%12.7 oranında saz semaisi; Zeybek müzik biçimini tanıyamayan öğrenciler bu müzik biçimine \%3.1 oranında deyiş, \%1.4 oranında peşrev, \%1.4 oranında İlahi; Bar müzik biçimini tanıyamayan öğrenciler bu müzik biçimine \%3.6 oranında longa, \%2.4 oranında nefes, \%2.4 oranında deyiş, \%2.4 oranında hora; Horon müzik biçimini tanıyamayan öğrenciler bu müzik biçimine \%1.8 oranında saz semaisi, \%1.4 oranında şarkı; Hora müzik biçimini tanıyamayan öğrenciler bu müzik biçimine \%15.9 oranında saz semaisi, \%9.9 oranında kırık hava; Halay müzik biçimini tanıyamayan öğrenciler bu müzik biçimine \%3.9 oranında bar \%2.1 oranında hora cevabını vermişlerdir.

\section{Tartışma ve Sonuç}

Araştırma sonucunda öğrencilerin en yüksek oranda tanıyabildikleri müzik biçimleri sırasıyla Horon (\%95.0), zeybek (\%86.0), halay (\%84.9) ve Bar (\%76.8) müzik biçimleri olduğu görülmektedir. Ayrıca öğrencilerin en düşük oranda tanıyabildikleri müzik biçimlerinin sırasıyla Saz Semaisi (\%12.3), Peşrev (\%18.3), Deyiş (\%18.7), Nefes (\%24.0), Hora (\%36.7), Longa (\%44) olduğu görülmüştür. Öğrenciler Mevlevi Ayini, Kırık Hava, Uzun Hava, Şarkı ve İlahi müzik biçimlerini ise \% 59.9-68.7 aralığında tanıyabilmişlerdir. Bu sonuç öğrencilerin Türk Halk Müziği müzik biçimlerini Türk sanat müziği biçimlerine göre daha fazla oranda tanıdıklarını göstermiştir. Bu durumun nedeni olarak Türk halk müziğinin Türk sanat müziğine göre toplum tarafından daha çok dinlenen ve tercih edilen bir müzik olması gösterilebilir (Atasoy, 2019; Cengiz, 2011; Kamalı ve Temiz, 2017; Sağır ve Öztürk, 2015; Yıldırım 
Şahin, 2019). Kuyucu'nun (2010) araştırmasında öğrencilerin büyük çoğunluğunun Türk sanat müziğini dinlemeyi tercih etmedikleri, Kılıç'ın (2016) araştırmasında ise ortaokul öğrencileri Türk halk müziğine olan ilgilerini gerçekçilik, yöresel ağız ve halk oyunlarıyla beraber kullanılabilmeleri boyutuyla dile getirdikleri belirlenmiştir. Bununla beraber öğrencilerin yüksek oranda tanıdıkları müzik biçimlerinin halk dansları müzikleri olduğu görülmektedir. Bu durum çalışma grubunun gelişim özellikleri dikkate alınd1ğında beklenen bir sonuç olarak gözükmektedir. Yapılan araştırmalar bu dönem öğrencilerinin müzik dinleme amaçlarının genellikle eğlence olduğunu (Bulut ve Altay, 2010; Kamalı ve Temiz, 2017; Sakar ve Maba, 2015) ve hareketli müzik tarzlarını tercih ettiklerini (Sakar ve Maba, 2015) göstermiştir. Nitekim Sloboda, O'Neill ve Ivaldi (2001) öğrencilerin müziğe karşı motivasyonunda zevk ve eğlencenin önemli bir unsur olduğunu, keyif aldıkları müziklere karşı tutumlarının daha olumlu olduğunu belirtmiştir. Türk halk müziği müzik biçimleri nişan, düğün, sünnet gibi çeşitli törenlerde tercih edilen bir müzik türüdür (Cengiz, 2011). Türk halk müziğinin bu biçimlerinin toplumumuzda yaygın olarak eğlence müziği olarak kullanılması da öğrenciler tarafından tanınmasında diğer bir neden olabilir.

Araştırmadan elde edilen diğer bir sonuç ise öğrencilerin genel puan dağılımının toplam 15 puan olduğu formdan ortalama olarak 7.15 puan almalarıdır. Bu sonuç öğrencilerin Türk müziği biçimlerini orta düzeyde tanıdıklarını göstermektedir. Sağer (2009), ortaokul öğrencileriyle yaptığı araştırmada geleneksel müzik türlerine ait kazanımların gerçekleşmesinde eksiklikler yaşandığına ulaşmıştır. Bu durum bu yaş dönemindeki öğrencilerin müzik ilgilerinin ve tercihlerinin daha çok popüler müzik türünde olmasından kaynaklı olabilir. Howell (2010) son yıllarda öğrencilerin geleneksel müziğe olan ilgilerinin azaldığı popüler müziğe karşı daha ilgili olduğunu belirtmiştir. Ülkemizde de öğrencilerle yapılan birçok araştırmada öğrencilerin en çok dinledikleri müzik türünün popüler müzik olduğu, Türk halk müziği ve Türk sanat müziği türlerini ise son sıralarda tercih ettikleri veya hiç tercih etmedikleri görülmüştür (Ang1 ve Şendurur, 2013; Bozkurt, Zahal ve Uyan, 2015; Bulut ve Altay, 2010; Doğan, 2019; Ertenli, 2014; Sakar ve Maba, 2015; Yurga, 2017). Bu sonucu etkileyen diğer bir unsur ise okullarda verilen müzik eğitiminin niteliği ile ilgili olabilir. Örneğin Bulut'un (2008) araştırmasında müzik öğretmenlerinin Türk Sanat Müziği ve Türk Halk Müziği konularının 
teorik kapsamının, repertuar eserlerinin bu yaş grubu öğrencilerinin öğrenme düzeyine tam olarak uygun olmadığını, öğrencilerin bu müzik türlerini öğrenmeye ve dinlemeye karşı ilgisiz ve isteksiz oldukları, öğrenmede zorlandıklarını belirttikleri sonucuna ulaşmıştır. Geleneksel müziklerin öğretimindeki sorunlar yalnızca ülkemizde değil yurtdışında yapılan araştırmalara da konu olmuştur. Grant (2017) yaptığı araştırmada geleneksel müziklerin genç nesillere aktarılmasında önemli sorunlar olduğunu belirtmiştir. Bu sorunlar devlet okullardaki yetersiz müzik eğitimi, geleneksel müzik türlerinin teknik olarak zorluğu, yerel müziklerin okul temelli müzik eğitimlerinde yer almaması, kırsal kesimdeki kültürel aktarımın azalmasından dolayı gençlerin örgün eğitim ve kültürel aktarım mekanizmalarının dışındaki yollardan geleneksel müziği öğrenmeleri, gençlerin geleneksel müziğe olan ilgisizliklerinden dolayı bu müziği öğrenmeye yönelik motivasyon eksikliği, sosyokültürel değişimler karşısında geleneksel müziklerin baskılanması, ekonomik zorluklar, gençlerin geleneksel müziği öğrenme fırsatlarının az olması ve popüler müzikleri daha fazla tercih etmeleri olarak sıralanmıştır. Ayrıca öğretmenlerin lisans eğitiminde aldıkları derslerin ortaokul derslerine yönelik olmaması (Bulut, 2008), öğretmenlerin geleneksel müzik konusunda yeterince bilgi sahibi olamamaları (Satomi, 2019), batı müziği kökenli öğretmenlerin geleneksel müziklere olan olumsuz tutumu bu müzik türlerinin öğrenilmesinin önündeki ortak engeller olarak sıralanmıştır (Dionyssiou, 2000; Satomi 2019). Ders saatlerinin yetersiz oluşu ve materyal eksikliği de belirtilen diğer sorunlar arasındadır (Bulut, 2008; Satomi, 2019).

Araştırma sonucunda öğrencilerin öğrenim gördükleri okulun bulunduğu sosyoekonomik çevrenin bazı Türk müziği biçimlerini tanımada anlamlı farklılık oluşturduğu görülmüştür. Yapılan bazı araştırmalar bu sonucu destekler niteliktedir. İmik (2007) bireylerin sosyoekonomik durumlariyla tercih edilen müzik türleri arasında yakın bir ilişki olduğunu belirtmiştir. İmik'e (2007) göre bireylerin gelir durumu ile kültürel beğenileri arasında yakın bir ilişki vardır. Bireylerin çoğu içine doğduğu ailenin sosyo-ekonomik statüsüne göre tercihler yapar. Çocuğun müziksel beğeni kültürünün meydana gelmesinde ailesinin, sosyal çevresinin ve model aldığı yetişkinlerin etkisi oldukça önemlidir. (Howell, 2010; İmik, 2007). Yapılan birçok araştırma sosyoekonomik çevrenin öğrencilerin müziğe olan tutumları, müzik tercihleri ve müzik performansı üzerinde etkili bir unsur olduğunu göstermiştir 
(Antmann, 2015; Nolin, 1973; Nolin ve Vander Ark; 1977; Philips, 2003; Pogonowski, 1985; Shaw ve Tomcala, 1976; Yıldırım Şahin, 2019). Örneğin İstanbullu (2009) araştırmasında kırsal kökenli ve kent kökenli öğrencilerin müzik profilleri arasında farklılıklar olduğunu belirlemiştir. Karakaş (2016) göre Türk sanat müziğinin, kentsel kökenli olması nedeniyle toplumun üst sınıfsal tabakasına hitap eden bir müzik anlayışı olduğunu belirmiştir. Kuyucu (2010) ise gelir düzeyi düşük öğrencilerin Türk sanat müziğine daha fazla ilgi duyduğu sonucuna ulaşmıştır. Sosyoekonomik farklılıkların müziğe olan yaklaşımlardaki etkisini öğrencilerin diğer alanlardaki düşük veya yüksek başarılarıyla açıklayan araştırmalar da bulunmaktadır (Nolin, 1973; Shaw ve Tomcala, 1976).

Araştırma sonucunda;

- Öğrencilerin tanımada güçlük çektiği müzik türlerine ilişkin ilgi çekici etkinliklerin artırılması

- Bazı tür ve biçimlere ilişkin dinletilerin derste artırılması tür ve biçimleri algılamada kolaylık sağlayacağından müzik öğretmenlerinin işitsel uyaranlara daha fazla ağırlık vermesi

- Farklı öğretim kademelerinde ve farklı sınıflarda benzer araştırmaların yapılması önerilebilir. 


\title{
EXTENDED ABSTRACT
}

\section{Examination of The 8th Grade Secondary School Students' Identification of Turkish Music Forms}

\author{
Kubilay Perdakçığlu -Murat Kamil İnanıcı \\ Atatürk University
}

The social and cultural importance and the function of influencing music can only be realized through music education in schools. The music gained to the student at school, his understanding of music and his taste become sustainable by settling in the family and society (Sun, 1969). It is quite difficult for a generation that moves away from its own culture to transfer the social culture to future generations (Imik, 2012). In contemporary music education, individuals or students are usually shaped in the final patterns of the musical tradition. For this reason, traditional music plays an important role in the general music education of the most developed societies (Uçan, 2018). Cesarone (1999) emphasized the importance of making sense of traditional culture and developing respect for their own culture by using traditional music samples in a qualified music education (act. Nevruz, 2018).

Every society has a musical art created within the framework of its national values and rules. Turkish music was born, shaped and developed within the framework of its customs, traditions and traditions, thus becoming a part of Turkish culture (Kardeş, 2013). Turkish music is a music that has its own characteristic and structural features. Being a makam is one of these features (Yahya-Kaçar, 2009). Traditional Turkish music consists of "Traditional Turkish Folk Music" and "Traditional Turkish Art Music". Traditional Turkish folk music is traditional music that reflects the common feelings and thoughts of the people, which has been burned, created and composed by folk artists who are always present in the people, and spread from language to language, from wire to wire, from ear to ear through changes and kneadings (Büyükyıldız, 2009). On the other hand, traditional Turkish art music developed and renewed with a single voice in the historical process; In this research, it is aimed to examine the middle school 8th grade students' recognition of Turkish music forms. "What is the level of 
students' recognition of Turkish music forms in the middle school 8th grade music lesson program?" question constitutes the problem statement of the research.

In this research, descriptive survey model, which is one of the quantitative research patterns, was used because it was aimed to examine the level of recognition of Turkish Music forms of middle school 8th grade students. The universe of the research was 284 8th grade students studying in secondary schools affiliated to the Directorate of National Education in Erzurum city center in the 2018-2019 academic year. "Personal Information Form" prepared by the researchers and "Turkish Music Forms Recognition Form" were used as a means of data collection in order to determine Turkish music forms' recognition status of middle school 8th grade students. First of all, the "MP3" formats of the work samples determined according to expert opinions were recorded by the researcher on the computer. The recorded works were listened to the students in the classroom by the researcher, and the students were selected to mark the format of each work individually from the "Recognition Forms of Turkish Music Forms" form. Since the item difficulties in the "Turkish Music Forms Recognition Form" prepared were considered the same, the internal consistency was calculated with the KR21 test (Alpha value $=.690$ ). Percentage and frequency analysis were made in the analysis of the data related to the sub-problems, and the intergroup recognition status of the socioeconomic environment was obtained by oneway ANOVA test.

As a result of the research, it is seen that the music formats that the students can recognize at the highest rate are Horon (95.0\%), zeybek $(86.0 \%)$, halay $(84.9 \%)$ and Bar $(76.8 \%)$. As a result of the research, it was concluded that the music formats that the students knew at the lowest rate were Saz Semaisi (12.3\%), Peşrev (18.3\%), Deyiş (18.7\%), Nefes (24.0\%), Hora (36.7\%), Longa (44\%). Students were able to recognize Mevlevi Ayini, Kırık Hava, Uzun Hava, Song and Divine music forms in the range of $59.9-68.7 \%$. This result showed that students knew Turkish Folk Music forms more than Turkish art music forms. This result may be due to the fact that Turkish folk music is more listened and preferred by society than Turkish art music (Atasoy, 2019; Cengiz, 2011; Kamalı ve Temiz, 2017; Sağır and Öztürk, 2015; Yıldırım Şahin, 2019). However, it is seen that the music forms that the students are familiar with are mostly folk dance music. This situation seems to 
be an expected result considering the developmental characteristics of the study group. The researches showed that the students' listening objectives in this period are generally entertainment (Bulut and Altay, 2010; Kamalı and Temiz, 2017; Sakar and Maba, 2015) and they prefer active music forms (Sakar and Maba, 2015). Another result obtained from the research is that students get an average of 7.15 points from the form, where the overall score distribution is 15 points in total. This result shows that students know Turkish music forms at a medium level. Sager (2009), in his research with middle school students, has reached the shortcomings in realizing the gains of traditional music genres. This may be due to the fact that the music interests and preferences of the students in this age period are mostly in popular music genre. As a result of the research, it was seen that the socioeconomic environment where the school where the students are studying creates a significant difference in recognizing some Turkish music forms. Some researches support this result. Imik (2007) stated that there is a close relationship between individuals' socioeconomic status and preferred music genres.

\section{Kaynakça / References}

Ang1, Ç. E. ve Şendurur, Y. (2013). Lise öğrencilerinin demografik özellikleri ile dinledikleri müzik türleri arasındaki ilişki. The Journal of Academic Social Science Studies, 33, 223-238.

Antmann, M. (2015). Socioeconomic status, instrumental music participation, and middle school student achievement. Unpublished doctoral dissertation. University of Central Florida, US.

Atasoy, M. U. (2019). Öğretmen adaylarının müzik dinleme alışkanlıklarının değerlendirilmesi : Kuitahya ili örneği. Turkish Academic Research Review, 4(1), 221234.

Barış, D.A. ve Özata, E. (2009). Sınıf öğretmenliği anabilim dalında alınan müzik öğretimi derslerinin öğretmenlik uygulamalarındaki yansımaları. Mehmet Akif Ersoy Üniversitesi Eğitim Fakültesi Dergisi, 9(18), 27- 41.

Bozkurt, S. S., Zahal, O. ve Uyan, Z. D. (2015). Ortaokul öğrencilerinin duygu durumlarına göre dinledikleri müzik türlerinin incelenmesi. The Journal of Academic Social Science Studies, 39, 541567.

Bulut, D. ve Altay, E. (2012). İlköğretim ikinci kademeöğrencilerinin müzik profilleri: Yozgat ili örneği. Kastamonu Eğitim Dergisi, 20(1), 237-254. 
Bulut, D. (2008). Illköğretim II. kademe müzik öğretmenlerinin geleneksel müziklerimizin öğretiminde karşllaştıkları sorunlar. Cumhuriyet Üniversitesi Sosyal Bilimler Dergisi, 32(1), 149-161.

Büyükyıldız, H. Z. (2009). Türk halk müziği-ulusal Türk müziği. İstanbul: Papatya Yayıncilik.

Cengiz, R. (2011). Sosyolojik bir olgu olarak müzik: Tokat örneği. Journal of International Social Research, 4(18), 363-378.

Çömlekçi, N. (2001). Bilimsel araştırma yöntemi ve istatistiksel anlamlllk sinamaları. Ankara: Bilim Teknik Yayınevi.

Dikici Sığırtmaç, A. (2014). Müzik ve gelişim. (Ed. İ. Artan.). Her yönüyle okul öncesi eğitim 6. Okul öncesi dönemde müzik eğitimi içinde (s. 15-30). Hedef Yayıncllk: Ankara.

Dionyssiou, Z. (2000). The effects of schooling on the teaching of Greek traditional music. Music education research, 2(2), 141-163.

Doğan, U. (2019). Ortaöğretim öğrencilerinin müzik beğeni ve tercihlerinin çeşitli değişkenler yönünden incelenmesi: Sivas/Zara örneği. Yayımlanmamış yüksek lisans tezi. Cumhuriyet Üniversitesi Sosyal Bilimler Enstitüsü, Sivas.

Emnalar, A. (1998). Tüm yönleriyle Türk halk müziği ve nazariyatı. İzmir: Ege Üniversitesi.

Ertenli, İ. (2014). Ortaokul 8. sinıföğrencilerinin ilköğretim müzik dersiöğretim programında yer alan müzik türlerini dinleme durumlarna ve programm müzik türü tercihleri üzerindeki etkisine ilişkin görüşleri. Yayımlanmamış yüksek lisans tezi. Gazi Üniversitesi Eğitim Bilimleri Enstitüsü, Ankara.

Fox, J. E. ve Schirrmacher, R. (2014). Çocuklarda sanat ve yaratıchlğın gelişimi. (N. Aral ve G. Duman, Çev.). Ankara: Nobel Yayıncilik.

Grant, C. (2017). Learning and teaching traditional music in Cambodia: Challenges and incentives. International Journal of Music Education, 35(1), 5-16.

Helvacı, Z. (2006). Kültürel kimlik bağlammda müzik kültürümüz ve AB süreci. Müzik Sanatımız ve AB Süreci Sempozyumu. Ankara: Sevda Cenap and Müzik Vakfi Yayınları.

HKSR. (2003). Membership of the curriculum development council committee on arts education. 03.07.2020 tarihinde https://www.edb.gov.hk/attachment/en/curriculum-development/kla/artsedu/references/music\%20complete\%20guide eng.pdf adresinden erişildi.

Howell, J. (2010). The attitudes and interests of adolescent middle school youth regarding traditional music instruction. Unpublished master dissertation. California State University, Long Beach. 
İmik, Ü. (2007). Sosyal statünün müziksel beğeniye etkileri. Yayımlanmamış yüksek lisans tezi. Erciyes Üniversitesi Sosyal Bilimler Enstitüsü, Kayseri.

İmik, Ü. (2011). Çizgi film müziklerinin yapısal olarak incelenmesi ve değerlendirilmesi. Yayımlanmamış doktora tezi. İnönü Üniversitesi Sosyal Bilimler Enstitüsü, Malatya.

İmik, Ü. (2012). Türk kültürünün yaşatılmasında müziğin önemi ve genç dinleyiciler üzerindeki etkileri. İnönü Üniversitesi Sanat ve Tasarmm Dergisi, 2(4), 47-59.

İstanbullu, S. (2009). İçanadolu bölgesinde güzel sanatlar ve spor liseleri müzik bölümünde eğitim gören kursal kökenli ve kent kökenli öğrencilerin müzik profillerinin incelenmesi. Yayımlanmamış yüksek lisans tezi. Niğde Üniversitesi Sosyal Bilimler Enstitüsü, Niğde.

Kamalı, C. ve Temiz, E. (2017). Ortaokul öğrencilerinin müzik tercihlerinin ve bu tercihleri etkileyen faktörlerin belirlenmesi. Fine Arts, 12(4), 280-298.

Karakaş, G. (2016). Geleneksel Türk sanat müziğinin Türk halk müziğiyle karşlaşttrarak incelenmesi. Yayımlanmamış yüksek lisans tezi. Adıyaman Üniversitesi Sosyal Bilimler Enstitüsü, Adıyaman.

Karasar, N. (2007). Bilimsel araştırma yöntemi (1. baskı). Ankara: Nobel Yayıncılık.

Kardeş, T. (2013). Mesleki müzik eğitimi veren devlet konservatuvarlarnndaki klâsik Türk müziği üslûp ve repertuvar eğitiminin içerik ve yöntem bakımindan incelenmesi. Yayımlanmamış yüksek lisans tezi. Afyon Kocatepe Üniversitesi Sosyal Bilimler Enstitüsü, Afyonkarahisar.

Kulıç, I. (2016). Ortaokul öğrencilerinin müzik ileilgili görüşlerinin incelenmesi. Ĕ̆itim ve Öğretim Araş̧trmalar Dergisi, 5(3), 360-371.

Kuyucu, M. M. (2010). Ortaöğretimde öğrenim gören öğrencilerin Türk sanat müziğine yaklaşımı. Yayımlanmamış yüksek lisans tezi. İstanbul Teknik Üniversitesi Sosyal Bilimler Enstitüsü, İstanbul.

MEB. (2018). Müzik dersi (9, 10, 11 ve 12. smuflar) öğretim programı. 17.11.2019 tarihinde http://mufredat.meb.gov.tr/ProgramDetay.aspx?PID=359 adresinden erişildi.

Nevruz, Ş. (2018). Ortaokul öğrencilerinin öğrenme stilleri, müzik ders kazanımlarmın gerçekleşme düzeyi ve derse yönelik tutumlarnn incelenmesi. Yaymmlanmamış yüksek lisans tezi. Necmettin Erbakan Üniversitesi Eğitimi Bilimleri Enstitüsü, Konya.

Nolin, W. H. ve Vander Ark, S. D. (1977). A pilot study of patterns of attitudes toward school music experiences, self-esteem and socio-economic status in elementary and junior high students. Contributions to Music Education, 5, 31-46. 
Nolin, W. H. (1973). Attitudinal growth patterns toward elementary school music experiences. Journal of Research in Music Education, 21, 123-134.

Phillips, S. L. (2003). Contributing factors to music attitude in sixth-,seventh, and eighthgrade students. Unpublished doctoral dissertation. University of Iowa, Iowa.

Pogonowski, L. M. (1985). Attitude assessment of upper elementary students in a process-oriented music curriculum. Journal of Research in Music Education, 33(4), 247-257.

Sağer, N. (2009). İlköğretim 6.7.8. sını müzik dersinde yer alan kazanımların öğrenciler tarafından değerlendirilmesi. Yayımlanmamış yüksek lisans tezi. Kırıkkale Üniversitesi Sosyal Bilimler Enstitüsü, Kırıkkale.

Sağır, A. ve Öztürk, B. (2015). Sosyolojik bağlamda müzik ve kimlik: Karabük üniversitesi örneği. Uşak Üniversitesi Sosyal Bilimler Dergisi, 8(2), 121-154.

Sakar, M. H. ve Maba, A. (2015). Ortaokul öğrencilerinin müziksel tercihleri ve dinleme pratikleri. Journal of International Social Research, 8(36), 980-996.

Satomi, O. (2019). Traditional music and world music in Japanese school education. Min Su Qu Yi, 203, 73-110.

Shaw, C. N. ve Tomcala, M. (1976). A music attitude scale for use with upper elementary school children. Journal of Research in Music Education, 24, 73-80.

Sloboda, J.A., O'Neil, S.A. ve Ivaldi, A. (2001) Functions of music in everyday life: An explanatory study using the experience sampling methodology. Musical Scientiae, 5(1), 9-32.

Sun, M. (1969). Türkiye'nin kültür-müzik-tiyatro sorunları. Ankara: Kültür Yayınları.

Şanl, Y. (2007). Türk müziği dizileri ve solfeji-1. Ankara: Marj Ajans.

Şenocak, E. (2005). Müziğin insan yaşamındaki yeri. Müzik Sempozyumu. Nisan 14 16), Kayseri.

Türkmen, U. (2010). Çocuğun bireysel toplumsal ve kültürel gelişiminde amatör müzik eğitiminin yeri problemleri ve çözüm önerileri. İlköğretim Online, 9(3), 960-970.

Uçan, A. (1996). Insan ve müzik insan ve sanat eğitimi (2. bask1). Ankara: Müzik Ansiklopedisi Yayınları.

Uçan, A. (2018). Müzik eğitimi: Temel kavramlar-ilkeler-yaklaşımlar ve Türkiye'deki durum. Ankara: Arkadaş Yayınları.

Uçan, A., Yıldız, G. ve Bayraktar, E. (1999). İköğretimde müziköğretimi, ilköğretimde etkili öğretme ve öğrenme öğretmen el kitabı. 9. modül. Burdur: Milli Eğitim Bakanlı̆̆1 Yayınları. 
Yıldırım Şahin, B. (2019). Sosyolojik açıdan müzik dinleme alışkanlklarnna etki eden etmenler: Bolu ili örneği. Yayımlanmamış yüksek lisans tezi. Abant İzzet Baysal Üniversitesi Sosyal Bilimler Enstitüsü, Bolu.

Yurga, M.C. (2017). Lise öğrencilerinin dinledikleri müzik türlerinin duygu durumlarna göre incelenmesi. Yayımlanmamış yüksek lisans tezi. İnönü Üniversitesi Eğitim Bilimleri Enstitüsü, Malatya.

\section{Kaynakça Bilgisi / Citation Information}

Perdakçıŏlu, K. ve İnanıcı, M. K. (2021). Ortaokul 8. sınıf öğrencilerinin Türk müziği biçimlerini tanıma durumlarının incelenmesi. OPUSUluslararası Toplum Araştırmaları Dergisi, 17(33), 477-500. DOI: 10.26466/opus.799734 